\section{Späte Freiheiten}

\author{
E. Taverna
}

Geschichten vom Altern, neue Lebensformen im Alter verspricht die Ausstellung im Landesmuseum Zürich vom 14. April bis 16. Juli 2000.

Blickfang ist auf allen Plakaten das Umschlagphoto vom Katalog, das strahlende Seniormodell aus München, eine elegante, schöne Frau von 84 Jahren. Sie haben anscheinend gut lachen, diese Alten. Der Soziologe und Philosoph Herbert Marcuse definiert diese späten Freiheiten: "Man will keine Karriere mehr, man kann keine mehr wollen. Der Wettlauf ist vorbei. Mit ihm: das Sich-anpassen-Müssen, das Einstecken-Müssen. Mit ihm: die Angst, den richtigen Zug zu versäumen. Mit ihm: die Sorge, aufs falsche Pferd zu setzen. Mit ihm: das Wiederkäuen der blödesten Prunksätze des Zeitgeistes.» Die Rede ist von der Lebensphase der Menschen zwischen 55 und 75 Jahren, der "New Generation" gesunder, fitter, mobiler und kaufkräftiger Stimmbürger, die vital und selbstbewusst die Zukunft der Industriestaaten bestimmen werden.

Irgendwo, zwischen normal und hinfällig, sucht die Ausstellung eine neue Bildsprache für diese zunehmend bestimmende Gesellschaftsgruppe. Nicht einmal das irdische Ende ist noch so, wie es einmal war. Der Einstieg über das Skelett im Grab zeigt ein sauberes Gerippe aus alter Zeit neben seinem modernen Nachfolger aus Knochen, Schrott und Sondermüll, aus Schrittmacher und Gelenkersatz. Der erste Themenbereich ist dem Körper gewidmet, wobei Nacktheit und Sexualität für Mann und Frau kein Tabu mehr sind. Neue Sehweisen werden vordemonstriert, der Begründer des Bodybuilding spannt seine 83jährigen Muskeln und ältere Frauen entdecken die Ästhetik schlaffer Brüste und runzliger Haut. Wachsmoulagen und Photos ergänzen Goyas fliegende Hexe oder Cranachs Jungbrunnen. Die klassische Kunst dämonisierte den gealterten weiblichen Körper. Erst die modernen Fotografinnen entdecken die Schönheit spätherbstlicher Körperlandschaften. Eine Schar junger Damen betrachtet vorsichtig-skeptisch die ausgestellten Akte. Sie mögen noch nicht die Begeisterung der Lehrerin teilen, die unermüdlich die Würde der emanzipierten Greisinnen betont. Vielleicht ahnen sie den Widerspruch zwischen dieser neuen Freiheit und dem Zwang der medizinisch-technisch machbaren Attraktivität.

Fünf Themenbereiche füllen die verwinkelten Räume im ersten Stock: Körper, Wohnen, Kommunikation, Mobilität und materielle Sicherung. Sie zeigen optimistisch die Kennzeichen einer "jungen alten» Generation. Die historisch zunehmende Selbständigkeit dominiert die Gegenüberstellung von Früher und Heute. Das Gesamtprojekt von Alltagskultur und Kunstgeschichte ist anspruchsvoll. Die Ausstellung verlangt konzentrierte Lesearbeit. Vieles ist klein geschrieben und spärlich beleuchtet. Oft sind die Texte auf leicht bewegliche Stoffbahnen gedruckt, was beim Lesen eine mittlere Übelkeit erzeugt. Der museumspädagogische Härtetest wird durch die ferne Toilette und den fehlenden Lift ergänzt. Ohne Lektüre des unentbehrlichen Kataloges und ohne Besuch des reichhaltigen Rahmenprogrammes bleibt die Schau ein Fragment, wenn auch ein sehenswertes, trotz der wenig behinderten- oder altersfreundlichen Anlage in der abbruchreifen Schlosskopie beim Hauptbahnhof.

Originell ist der Schrank, der das alternde Körperinnere verbirgt. Erst die geöffneten Türen zeigen, was die Zeit an Venenknäueln, Verkalkungen, Verfettungen und Flecken bereithält. Zum Glück lassen sich die unappetitlichen Einsichten wieder leicht verschliessen. Die neue Mobilität und die eigenen vier Wände sind erfreulichere Themen. Zum Beispiel die SBB als hierzulande grösstes Freizeitunternehmen für den Un-Ruhestand, der sich nicht mehr mit Billigcarreisen über vier Pässe und Rheumadecken zufriedengibt. Zur Alters-WG und Seniorenresidenz gehört die Garage. Und Geld. Die Alterssicherung nimmt auch optisch einen wichtigen Platz ein. "Spare in der Zeit, so hast du in der Not" sagt die alte Spardose. "Alt, reich und zinsbesessen" oder "Aktien statt Almosen, die Macht der grauen Schläfen" oder "Was werden die Jungen mit uns machen?» titeln die neuen Schlagzeilen. Armut und Freiheit vertragen sich nicht. Ohne neue Verträge der Generationen bleiben die süssen Freiheiten das Privileg einer Minderheit, die es schon immer besser hatte. Ein junger Mann im Rollstuhl und eine hinkende Frau, die ihren schmerzhaften Rücken stützt, betrachten die Plakate der "Stiftung für das Alter». Die beiden erinnern daran, dass es, gemessen am Ausspruch von Marcuse, neben den späten auch noch die "unfreiwilligen Freiheiten» gibt. 